\title{
Circulating P-Selectin Glycoprotein Ligand 1 and P-Selectin Levels in Obstructive Sleep Apnea Patients
}

\author{
P. Horváth ${ }^{1}$ - Z. Lázár ${ }^{1} \cdot$ G. Gálffy ${ }^{1} \cdot$ R. Puskás ${ }^{1} \cdot$ L. Kunos $^{1} \cdot$ Gy. Losonczy ${ }^{1} \cdot$ M. Mészáros $^{1} \cdot$ Á. D. Tárnoki ${ }^{2}$. \\ D. L. Tárnoki ${ }^{2} \cdot$ A. Bikov ${ }^{1}$
}

Received: 24 July 2019 / Accepted: 2 December 2019 / Published online: 2 January 2020

(C) The Author(s) 2019

\begin{abstract}
Purpose Obstructive sleep apnea (OSA) is characterized by chronic intermittent hypoxia which induces inflammation in blood vessels leading to the development of cardiovascular comorbidities. Several studies implicated the role of P-selectin in vascular inflammation of OSA. P-selectin glycoprotein ligand 1 (PSGL-1) is the main activator for P-selectin and is involved in immune cell trafficking. However, PSGL-1 has not been analyzed in OSA. The aim of the study was to investigate plasma PSGL-1 and P-selectin levels to have a deeper understanding on their interaction in obstructive sleep apnea.

Methods Fifty-one untreated patients with OSA and 42 non-OSA controls were recruited. Plasma PSGL-1 levels were determined in evening and morning samples, P-selectin levels were analyzed in morning samples using commercially available ELISA kits. Polysomnography was performed in all participants. OSA was defined by an apnea-hypopnea index $\geq 5 / \mathrm{h}$. Results PSGL-1 levels did not differ between controls and OSA patients either in the evening or in the morning. Although, there was no difference between controls $(16.9 / 6.8-40.8 \mathrm{ng} / \mathrm{ml})$ and patients with OSA $(19.6 / 8.4-56.8, p=0.24)$, patients with severe OSA had increased plasma P-selectin levels $(25.6 / 8.4-56.8 \mathrm{ng} / \mathrm{ml})$ compared to mild OSA patients (14.1/8.5-35.3 ng/ $\mathrm{ml}, p=0.006)$ and controls $(p=0.03)$.

Conclusions P-selectin expression relates to disease severity suggesting a pathophysiological role in endothelial cell activation. PSGL-1 levels are unaltered in OSA, suggesting an alternative activation pathway for P-selectin in OSA.
\end{abstract}

Keywords Systemic inflammation $\cdot$ Sleep apnea $\cdot$ Comorbidities $\cdot$ Adhesion molecules

\section{Introduction}

Obstructive sleep apnea (OSA) is characterized by repetitive complete or partial collapse of the upper airways and consequential intermittent hypoxia during sleep. Patients with OSA have a higher risk for hypertension, cardiovascular disease and type-2 diabetes mellitus [1].

Chronic intermittent hypoxia leads to the production of pro-inflammatory mediators, such as interleukin $1 \beta$ (IL-1 $\beta$ ), IL-6 and tumor necrosis factor- $\alpha$ [2]. These, together with hypoxia itself induce the expression of adhesion molecules, such as P-selectin. P-selectin is expressed upon stimulation

P. Horváth

horvath.peter2@med.semmelweis-univ.hu

1 Department of Pulmonology, Semmelweis University, Tömő utca 25-29, Budapest, Hungary

2 Department of Radiology, Semmelweis University, Budapest, Hungary by thrombin [3], hypoxia [4] or cytokines [5] by platelets and endothelial cells, however platelet P-selectin expression may be less important in OSA compared to endothelial P-selectin [6, 7]. P-selectin enhances the adhesion between leukocytes and endothelial cells thus slowing down the rolling of leukocytes and facilitating their extravasation. P-selectin has extensively been investigated in OSA [6-12] with some studies reporting elevated blood P-selectin levels $[8,11,12]$, but not all $[6,7,10]$. A potential explanation for the contradictory findings could be the presence of comorbid obesity, as one study reported no difference in circulating P-selectin levels between OSA and body mass index (BMI)-matched controls [6]. In addition, blood P-selectin concentrations were related to BMI, but not to the indices of disease severity in another study [8], however this has been contradicted by a further report [10]. Nevertheless, as OSA is frequently associated with obesity [13] which may itself induce systemic inflammation [14], potential effect of 
obesity has to be taken into consideration when interpreting the data.

P-selectin glycoprotein ligand 1 (PSGL-1) is expressed primarily on the surface of leukocytes [15], but endothelial cells and platelets can also express PSGL-1, albeit in a smaller quantity [16]. Its expression in platelets is induced by thrombin [17], which levels were reported to be increased in OSA [8]. There are no data available if inflammatory cytokine cascade seen in OSA can lead to an increased expression of PSGL-1 in leukocytes. Rather, it seems that inflammation may reconfigure PSGL-1 location on leukocytes to facilitate their binding [18]. In addition, appropriate glycosylation of PSGL-1 is essential for P-selectin binding and optimal leukocyte rolling $[18,16]$ and glycosylation is increased in active lymphocytes [18]. On the contrary, PSGL-1 is downregulated in apoptotic cells [19]. OSA is characterized by increased levels of pro-apoptotic [7] and decreased concentration of anti-apoptotic [20] molecules. The main receptor for PSGL-1 is P-selectin [21]. The main function for PSGL-1 is to facilitate leukocyte trafficking through endothelial cells. In addition, PSGL-1 has both pro-inflammatory role by inducing IL-8 production [22] and immunoregulatory effects by supporting regulatory $\mathrm{T}$-cell differentiation [16] and inducing the expression of immunosuppressive IL-10 and transforming growth factor- $\beta$ [23]. The levels of both molecules were found to be reduced in OSA [24]. Although PSGL-1 is an essential molecule for leukocyte differentiation and their trafficking during inflammation, its role in inflammatory diseases is not fully understood [16, 18]. However, PSGL-1 has not been studied in OSA yet.

Sleep fragmentation, another hallmark of OSA leads to an altered production of circulating hormones and cytokines.[7] Investigating evening to morning changes of inflammatory biomarkers may explore acute effects of disturbed sleep. In addition, this holds important methodological considerations, when to collect samples from OSA patients to study inflammatory pathways.

The aim of the study was to analyze the levels of circulating PSGL-1 in OSA. We compared evening to morning PSGL-1 concentrations and correlated with markers of OSA severity and comorbidities. PSGL-1 levels were investigated with its receptor, the P-selectin.

\section{Materials and Methods}

\section{Subjects and Design}

Ninety-three participants were recruited from those patients who were referred to the Sleep Unit of the Department of Pulmonology, Semmelweis University due to suspected OSA (i.e. snoring, witnessed apneas, daytime somnolence). None of the patients had previously been diagnosed with OSA, nor had they been treated with continuous positive airway pressure (CPAP) or mandibular advancement devices (MAD). Exclusion criteria included any uncontrolled chronic disease, history of any malignancy within 10 years, and infection within 2 months. Data for screen failures were not captured.

In the evening, after filling out the Epworth Sleepiness Scale (ESS) and taking medical history, venous blood was taken into EDTA tubes for PSGL-1 measurement. This was followed by an attended full-night polysomnography. The following morning blood pressure was measured, and blood collection was performed in EDTA tubes for plasma P-selectin and PSGL-1 as well as in red top tubes for serum C-reactive protein (CRP), glucose, total cholesterol, high density lipoprotein cholesterol (HDL-C), low density lipoprotein cholesterol (LDL-C) and triglyceride measurements. Blood was sampled at fasting conditions and before taking any medication.

The study was approved by the local Ethics Committee (Semmelweis University, TUKEB 30/2014) and informed consent was obtained from all participating volunteers.

\section{ELISA Measurements}

EDTA-treated blood samples were centrifuged within $2 \mathrm{~h}$ at $1500 \mathrm{RPM}$ for $10 \mathrm{~min}$ at $4{ }^{\circ} \mathrm{C}$. Immediately following centrifugation, plasma was separated into $250 \mu \mathrm{L}$ aliquots which were stored at $-80^{\circ} \mathrm{C}$ until analysis. Samples were thawed just before the ELISA measurements. PSGL-1 and P-selectin levels were measured using a commercially available ELISA kits (Abcam Human PSGL-1 ELISA kit and Sigma-Aldrich Human P-selectin ELISA kit) according to the manufacturers' instructions in duplicates. We reported the mean values of the two measurements. We measured PSGL1 levels in samples taken in the evening and in the morning, P-selectin levels were analyzed in the morning samples. Intra assay variability was $6.35 \%$ for P-selectin and $25.46 \%$ for PSGL-1.

\section{Polysomnography}

Polysomnography was performed as it was described previously [7] using Somnoscreen Plus Tele PSG (Somnomedics GMBH Germany). Electroencephalogram, electrooculogram and electromyogram, thoracic and abdominal respiratory excursions, breath sounds, nasal pressure, electrocardiogram and oxygen saturation were recorded. Sleep stages, movements and cardiopulmonary events were scored manually according to the American Academy of Sleep Medicine (AASM) guideline [25]. Total sleep time (TST), sleep period time (SPT) and minimum oxygen saturation $\left(\mathrm{MinSatO}_{2}\right)$ were recorded. Apnea-hypopnea index (AHI), respiratory disturbance index (RDI), oxygen desaturation index (ODI), arousal index (AI) and total sleep time spent with 
oxygen saturation below 90\% (TST90\%) were calculated. An $\mathrm{AHI} \geq 5 / \mathrm{h}$ was diagnostic for OSA.

\section{Statistical Analysis}

Shapiro-Wilks test was used to test to assess normality which showed non-parametric distribution for P-selectin and PSGL-1 levels. Mann-Whitney $U$-test and Chi-square test were used to compare clinical and demographic characteristics as well as biomarker levels between the OSA and control groups. We applied Kruskal-Wallis test, followed by the Dunn's test to investigate the differences in biomarker levels among the OSA severity groups. Plasma biomarker levels were correlated with clinical variables using the Spearman's test. All tests were carried out with R v. 3.1.3. Diagrams were plotted with the ggplot2 package for R. Kruskal Wallis and Dunn's test were performed with the dunn.test package for R. A sample size of 93 was estimated to find significant differences with an alpha of 0.05 , a beta of 0.8 and an effect size of $>0.40$ with respect to the asymptotic relative efficiency of non-parametric tests. $p$ values $<0.05$ were considered significant. Data are presented as mean \pm SD or median/range.

\section{Results}

\section{Patient Characteristics}

Following polysomnography, 51 patients were diagnosed with OSA ( $44 \pm 15$ years). Sixteen patients had mild OSA (AHI 5-14.9 events/h), 15 had moderate (AHI 15-29.9 events/h) and 20 had severe (AHI > 30 events/h) disorder. Subjects' characteristics and comparisons between the OSA and control groups are summarized in Table 1.

\section{Circulating PSGL-1 Levels}

PSGL-1 levels did not differ between controls and OSA patients either in the evening or in the morning (494.0/46.9-802.1 U/ml vs. 452.5/254.2-1265.9 U/ml, $p=0.67$ in the morning, and $480.2 / 41.3-1027.6 \mathrm{U} / \mathrm{ml}$ vs. $497.5 / 50.2-1054.7 \mathrm{U} / \mathrm{ml}, p=0.70$ in the evening in controls and OSA patients respectively). Similarly, PSGL-1 levels did not change from evening to morning in either group (both $p>0.05$, Fig. 1.). There was no difference in plasma PSGL-1 levels among the different OSA severity groups at either time point (Table 2). However, there was a significant correlation between the evening and morning PSGL- 1 levels $(\rho=0.27$, $p=0.02$ ). There was a trend toward higher PSGL-1 levels in obese OSA patients in the morning (530.7/291.1-1130.8 U/ $\mathrm{ml}$ vs. 413.4/254.2-1265.2 U/ml, $p=0.06$ ) compared to nonobese OSA.
Table 1 Patient characteristics of our study population

\begin{tabular}{llll}
\hline & Control $N=42$ & OSA $N=51$ & $p$ value \\
\hline Age (years) & $45 \pm 16$ & $55 \pm 12$ & $<0.01$ \\
Gender (male\%) & 14 & 68 & $<0.01$ \\
BMI (kg/m ${ }^{2}$ ) & $24.33 \pm 4.66$ & $31.18 \pm 6.20$ & $<0.01$ \\
Hypertension (\%) & 30 & 72 & 0.01 \\
Diabetes (\%) & 14 & 21 & 0.23 \\
Asthma (\%) & 9 & 3 & 0.55 \\
Aspirin use (\%) & 4.7 & 17.6 & 0.11 \\
Clopidogrel use (\%) & 2.38 & 3.9 & 1 \\
Statin use (\%) & 2 & 29 & $<0.01$ \\
Ever-smokers (\%) & 9 & 19 & 0.28 \\
ESS (points) & $5.94 \pm 3.29$ & $6.76 \pm 3.70$ & 0.29 \\
AHI (events/h) & $2.1 \pm 1.5$ & $31 \pm 26.7$ & $<0.01$ \\
RDI (events/h) & $11.3 \pm 6.4$ & $41.1 \pm 26.2$ & $<0.01$ \\
ODI (events/h) & $1.21 \pm 1.15$ & $28.75 \pm 26.92$ & $<0.01$ \\
MinSat (\%) & $90.72 \pm 3.22$ & $79.34 \pm 10.08$ & $<0.01$ \\
TST (min) & $379.21 \pm 64.76$ & $394.6 \pm 82.66$ & 0.38 \\
TST90\% (min) & $0.28 \pm 1.37$ & $14.68 \pm 21.26$ & $<0.01$ \\
AI (events/h) & $45.73 \pm 17.27$ & $45.02 \pm 24.75$ & 0.89 \\
SPT & $416.08 \pm 52.74$ & $432.48 \pm 70.75$ & 0.27 \\
\hline AHI & & & \\
\hline
\end{tabular}

$A H I$ apnea-hypopnea index, BMI body mass index, ESS Epworth Sleepiness Scale, RDI respiratory disturbance index, ODI oxygen desaturation index, TST total sleep time, TST90\% total sleep time with saturation under $90 \%, A I$ arousal index, $S P T$ sleep period time

\section{Circulating P-selectin levels}

There was no difference between OSA patients and controls in P-selectin levels $(p>0.05)$. However, circulating P-selectin levels were significantly different among the OSA severity groups (Kruskal-Wallis test, $p=0.01$, Table 2). After post-hoc testing we found that patients with severe OSA had increased plasma P-selectin levels compared to mild OSA patients $(p=0.006)$ and controls $(p=0.03$, Fig. 2$)$.

\section{Circulating P-Selectin Levels and Comorbidities}

There was a trend for elevated P-selectin levels in hypertensive patients with OSA $(N=37,22.9 / 8.4-56.8 \mathrm{ng} /$ $\mathrm{ml})$ compared to patients without hypertension $(N=14$, $13.7 / 10.6-35.3 \mathrm{ng} / \mathrm{ml}, p=0.057)$. There was no difference between controls with $(N=13,14.5 / 6.8-40.8 \mathrm{ng} /$ $\mathrm{ml})$ and without $(N=29,18.6 / 12.6-24.6 \mathrm{ng} / \mathrm{ml}, p=0.31)$ hypertension.

P-selectin was significantly higher in obese OSA patients (BMI $\geq 30 \mathrm{~kg} / \mathrm{m}^{2}, N=26,29.9 / 8.4-56.8 / \mathrm{ng} / \mathrm{ml}$ ) compared to non-obese patients $(N=25,13.7 / 8.5-38.3 \mathrm{ng} / \mathrm{ml}, p=0.003)$. Only two control participants were obese, hence no comparison has been performed in obese and non-obese controls. 
Fig. 1 PSGL-1 levels in our population. There was no difference between the OSA severity groups. There was no difference between PSGL-1 levels in the morning and in the evening

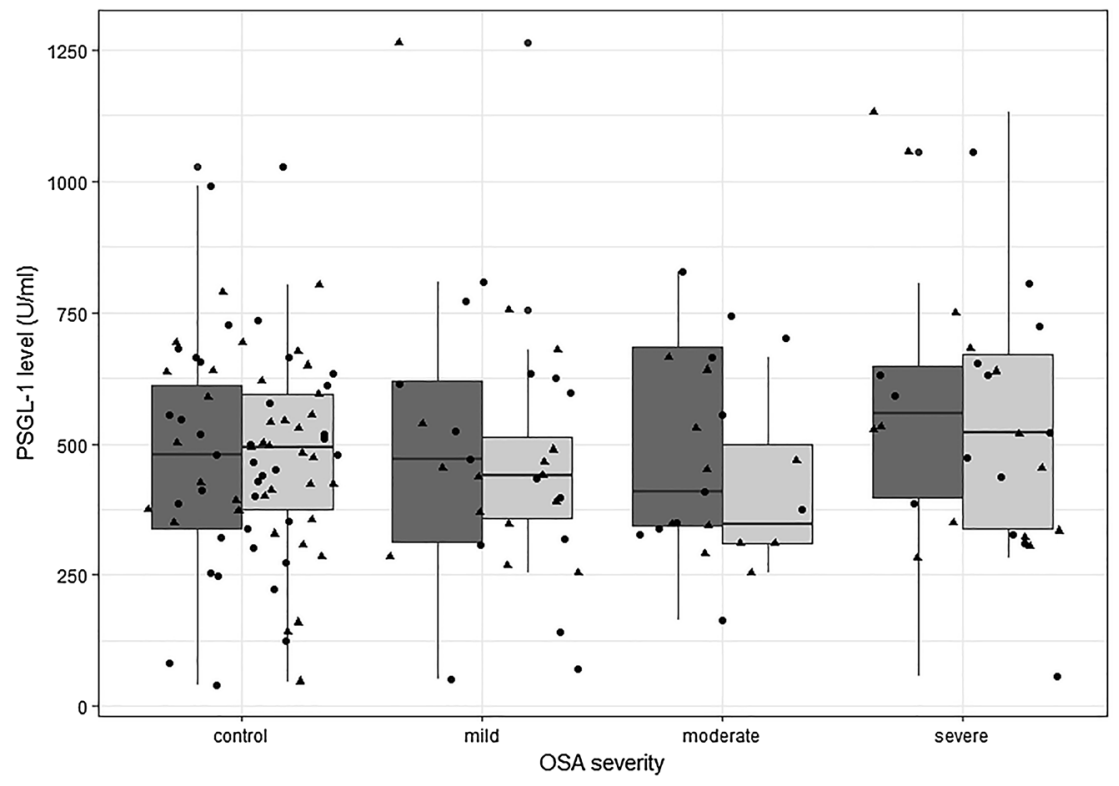

Daytime

率 evening

morning

Table 2 PSGL-1 and P-selectin levels in the different severity groups. PSGL-1 shows no significant difference, however P-selectin is significantly higher in the severe OSA group compared to controls and mild patients (post-hoc Dunn-test)

\begin{tabular}{llllll}
\hline & Controls & OSA (mild) & OSA (moderate) & OSA (severe) & $p$ value (KW-test) \\
\hline PSGL-1 (morning) U/ml & $494.0 / 47.0-802.1 /$ & $439.7 / 254.2-1265.2 /$ & $347.1 / 254.7-663.6 /$ & $522.0 / 283.0-1130.8 /$ & 0.43 \\
PSGL-1 (evening) U/ml & $480.2 / 41.3-1027.7 /$ & $470.4 / 50.2-808.6 /$ & $407.5 / 163.8-828.5 /$ & $556.4 / 55.8-1054.7 /$ & 0.78 \\
P-selectin (morning) ng/ml & $16.9 / 6.8-40.8 /$ & $14.1 / 8.5-35.3 /$ & $17.1 / 9.3-48.9 /$ & $25.6 / 8.4-56.8 /$ & $0.01 *$ \\
\hline
\end{tabular}

$K W$-test Kruskal-Wallis test

*Statistical significance

Fig. 2 P-selectin levels in our study group. P-selectin level was significantly higher in the severe group compared to controls and mild OSA patients

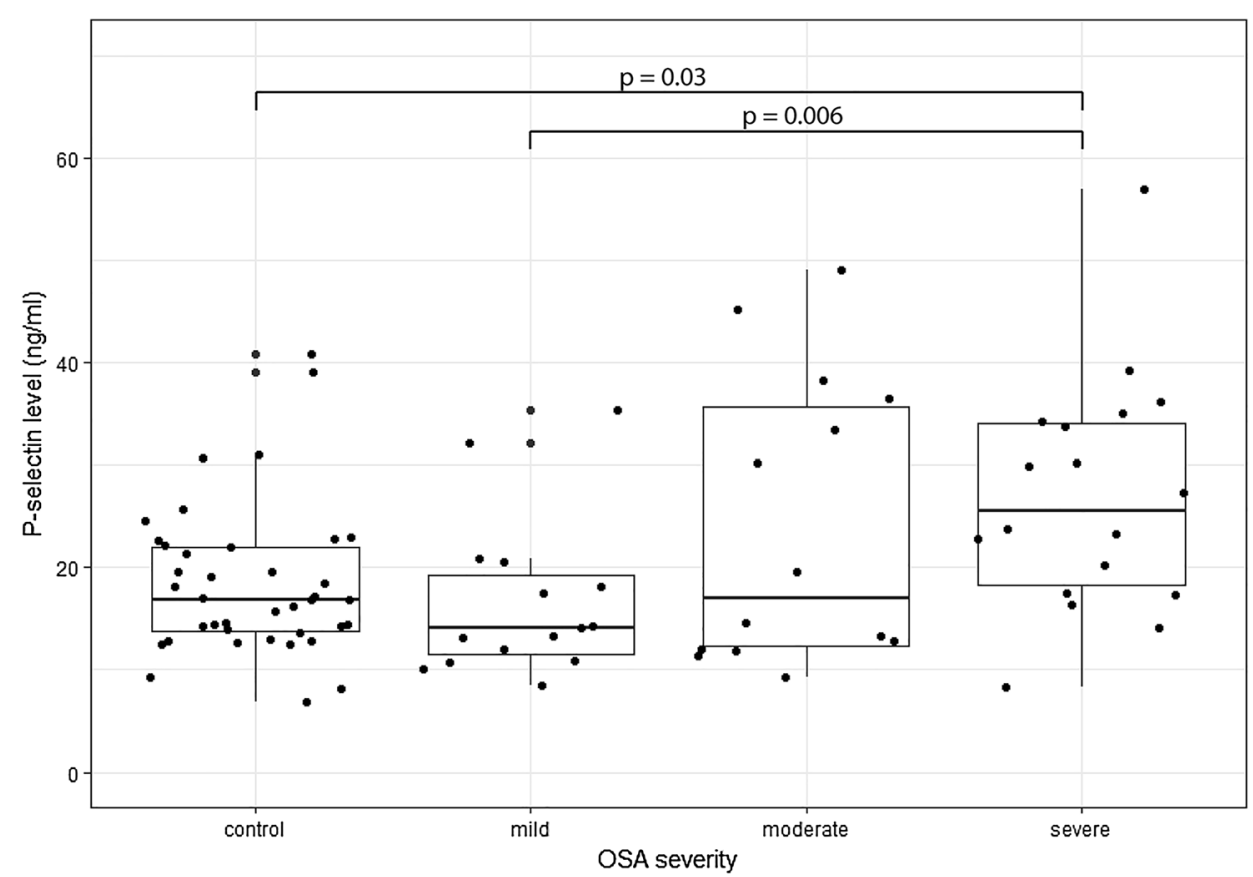


However, there was no difference in P-selectin between nonobese OSA and non-obese controls $(p=0.29)$.

\section{Correlation Between Biomarkers and Clinical Parameters}

We found no correlation between plasma PSGL-1 levels and any other demographic or clinical parameters, including indices of OSA severity (all $p>0.05$ ).

$\mathrm{P}$-selectin levels showed a positive correlation with AHI $(\rho=0.24, p=0.02)$, ODI $(\rho=0.29, p=0.005)$, RDI $(\rho=0.29$, $p=0.005)$ and BMI $(\rho=0.37, p<0.001)$, systolic and diastolic blood pressure in the morning ( $\rho=0.30, p=0.005$ and $\rho=0.34, p=0.001$ respectively) and fasting glucose level $(\rho=0.38, p=0.001)$. There was no correlation between plasma P-selectin concentrations and any other investigated variable.

There was no correlation between smoking (either status or pack years) and circulating P-selectin or PSGL-1 levels.

\section{Correlation Between P-Selectin and PSGL-1 Levels}

There was no correlation between P-selectin and PSGL-1 levels either measured in the morning or evening either when all subjects were investigated together, or when patients with OSA or control volunteers were analyzed separately. Analyzing the subgroups, a trend for a moderate correlation between P-selectin and morning PSGL-1 were found in severe OSA patients $(\rho=-0.53, p=0.07)$.

\section{Discussion}

In this study, we investigated the circulating levels of PSGL-1 in OSA together its receptor, P-selectin. We found no difference in PSGL-1 between patients with OSA and control participants, nor was there any overnight change detected. In contrast, there was a significant increase in P-selectin levels in severe OSA patients. However, these results should be interpreted carefully as plasma P-selectin levels were related to obesity apart from OSA severity. Our results suggest that there is no further increase in the expression of PSGL-1 in OSA and enhanced P-selectin in severe disease acts through an unaltered quantity of PSGL-1.

Systemic inflammation plays a role in the development of cardiovascular comorbidities in OSA. Although CPAP is an effective treatment in sleep apnea, it does not acute reduce cardiovascular events in cardiovascular disease [26]. A potential reason could be the fact that CPAP does not change the levels of inflammatory mediators [27]. This emphasizes the need of understanding the elements of systemic inflammation characterizing OSA to identify potential targets for drug development. The current study suggests that PSGL-1 is not altered in OSA, and future studies should investigate different inflammatory pathways.

We measured soluble PSGL-1 which may not necessarily reflect membrane bound PSGL-1 concentrations. It is known that soluble PSGL-1 increases after granulocyte colony-stimulating factor, granulocyte-macrophage colony-stimulating factor, lipopolysaccharide challenge and metalloproteases may cleave membrane bound PSGL-1 as well [16]. The levels of circulating metalloproteases are higher in OSA [28]. The unchanged concentration of soluble PSGL-1 in OSA may be due to balance between events leading to increased cleavage and decreased production of this molecule.

Confirming some previous results $[6,7,10]$, we did not find a significant difference in plasma P-selectin levels between OSA and controls. On the contrary, in line with some previous findings [9, 11, 29] severe OSA was associated with higher plasma P-selectin concentrations which were directly related to markers of disease severity (i.e. AHI, ODI and RDI). This is not entirely surprising as mild OSA is associated with the activation of some anti-inflammatory systems [30], suggesting that mild and more severe patients should be investigated separately when analyzing inflammatory mechanisms in OSA. Nevertheless, the relationship between P-selectin levels and disease severity on one hand suggests that enhanced intermittent hypoxia is responsible for increased P-selectin expression. However, on the other hand, P-selectin increase may be due to comorbid obesity, as we found a correlation between P-selectin levels and BMI, and P-selectin levels were higher in obese patients with OSA. Furthermore, there was no difference in P-selectin when non-obese OSA was compared to non-obese controls. OSA is frequently associated with obesity [13] which may itself induce systemic inflammation [14]. Previous studies showed that despite improvement in AHI, neither CPAP [8], nor MAD [12] altered circulating P-selectin levels. This suggests that possibly obesity is a more potent factor maintaining high $\mathrm{P}$-selectin concentrations than intermittent hypoxia. To test this, trials combining CPAP with weight loss programs are required with an aim to investigate $\mathrm{P}$-selectin in OSA. A previous study reporting high P-selectin levels in OSA found a significant association with BMI, but not disease severity [8]. In addition, no difference in platelet P-selectin expression was observed when patients with OSA were compared to weight-matched controls [6]. There was also a tendency for higher plasma P-selectin levels in OSA patients with comorbid hypertension. Interestingly, this difference was not present in non-OSA subjects. In addition, $\mathrm{P}$-selectin levels were related to blood pressure results. This emphasizes that P-selectin may play a role in hypertension and subsequent atherosclerosis characterizing OSA [31].

Sleep fragmentation may induce systemic inflammation [32]. However, neither PSGL-1, nor P-selectin levels were 
influenced by sleep quality indices. This is in line with a previous study reporting no differences in P-selectin levels between sleepy and non-sleepy patients with OSA [10]. There was no correlation between these molecules and Epworth sleepiness score, nor PSGL-1 levels changed after sleep. Our results suggest that sleep does not influence the levels of PSGL-1 itself.

A potential limitation of the study that the controls and patients with OSA were not matched. Patients with OSA were older, had higher BMI, had higher prevalence of males, hypertension and statin use. This is not surprising as these factors are associated with OSA [13]. Most notably, there was a significant association between plasma P-selectin levels and hypertension as well as BMI. Therefore, increased levels observed in severe OSA must be interpreted carefully. Of note, neither P-selectin, nor PSGL-1 concentrations were related to age, gender or medication usage, still because the current study was not powered to investigate these relationships, future studies should aim for matching OSA and control groups.

In summary, neither P-selectin nor PSGL-1 levels were altered in OSA. However, unlike PSGL-1, P-selectin concentrations were increased in severe OSA suggesting that either intermittent hypoxia or more probably comorbid obesity lead to endothelial and/or platelet activation expressing P-selectin. However, unchanged PSGL-1 does not rule out the increased activation of P-selectin on the endothelium in severe OSA and consequently, the accelerated extravasation of leukocytes as functional changes in PSGL-1 might facilitate ligand-receptor binding.

Acknowledgements Open access funding provided by Semmelweis University (SE). The authors are grateful to Elektro-Oxigén Inc. for providing polysomnographic devices and Mrs. Monika Banlaky for her assistance in polysomnographic measurements. The study was supported by Hungarian Respiratory Society grant to Peter Horvath and David Laszlo Tarnoki as well as Semmelweis University grant to Laszlo Kunos. This publication was supported by the Janos Bolyai Research Scholarship of the Hungarian Academy of Sciences to Andras Bikov. Andras Bikov is supported by the NIHR Manchester BRC. Martina Meszaros was supported by EFOP-3.6.3-VEKOP-16-2017-00009.

Funding The study was funded by Hungarian Academy of Sciences (János Bólyai Scholarship) and Hungarian Pulmonology Foundation (Scientific Scholarship).

\section{Compliance with Ethical Standards}

Conflict of interest The authors declare that they have no conflict of interest.

Ethical Approval All procedures performed in studies involving human participants were in accordance with the ethical standards of the institutional and/or national research committee and with the 1964 Helsinki declaration and its later amendments or comparable ethical standards. The study was approved by the local Ethics Committee (Semmelweis
University, TUKEB 30/2014) and informed consent was obtained from all participating volunteers.

Open Access This article is licensed under a Creative Commons Attribution 4.0 International License, which permits use, sharing, adaptation, distribution and reproduction in any medium or format, as long as you give appropriate credit to the original author(s) and the source, provide a link to the Creative Commons licence, and indicate if changes were made. The images or other third party material in this article are included in the article's Creative Commons licence, unless indicated otherwise in a credit line to the material. If material is not included in the article's Creative Commons licence and your intended use is not permitted by statutory regulation or exceeds the permitted use, you will need to obtain permission directly from the copyright holder. To view a copy of this licence, visit https://creativecommons.org/licenses/by/4.0/

\section{References}

1. Punjabi NM, Beamer BA (2009) Alterations in glucose disposal in sleep-disordered breathing. Am J Respir Crit Care Med 179(3):235-240. https://doi.org/10.1164/rccm.200809-1392OC

2. Kent BD, Ryan S, McNicholas WT (2011) Obstructive sleep apnea and inflammation: relationship to cardiovascular comorbidity. Respir Physiol Neurobiol 178(3):475-481. https:// doi.org/10.1016/j.resp.2011.03.015

3. Kameda H, Morita I, Handa M, Kaburaki J, Yoshida T, Mimori T, Murota S, Ikeda Y (1997) Re-expression of functional P-selectin molecules on the endothelial cell surface by repeated stimulation with thrombin. Br J Haematol 97(2):348-355

4. Closse C, Seigneur M, Renard M, Pruvost A, Dumain P, Belloc F, Boisseau MR (1996) Influence of hypoxia and hypoxiareoxygenation on endothelial P-selectin expression. Haemostasis 26(Suppl 4):177-181. https://doi.org/10.1159/000217296

5. Gotsch U, Jager U, Dominis M, Vestweber D (1994) Expression of P-selectin on endothelial cells is upregulated by LPS and TNF-alpha in vivo. Cell Adhes Commun 2(1):7-14

6. Rahangdale S, Yeh SY, Novack V, Stevenson K, Barnard MR, Furman MI, Frelinger AL, Michelson AD, Malhotra A (2011) The influence of intermittent hypoxemia on platelet activation in obese patients with obstructive sleep apnea. J Clin Sleep Med 7(2): $172-178$

7. Bikov A, Kunos L, Pallinger E, Lazar Z, Kis A, Horvath G, Losonczy G, Komlosi ZI (2017) Diurnal variation of circulating microvesicles is associated with the severity of obstructive sleep apnoea. Sleep Breath 21(3):595-600. https://doi.org/10.1007/ s11325-017-1464-y

8. Robinson GV, Pepperell JC, Segal HC, Davies RJ, Stradling JR (2004) Circulating cardiovascular risk factors in obstructive sleep apnoea: data from randomised controlled trials. Thorax 59(9):777-782. https://doi.org/10.1136/thx.2003.018739

9. Jurado-Gamez B, Bujalance Cabrera C, Caballero Ballesteros L, Marin Hinojosa C, Munoz Cabrera L, Perez-Jimenez F, LopezMiranda J (2012) Association of cellular adhesion molecules and oxidative stress with endothelial function in obstructive sleep apnea. Int Med (Tokyo, Japan) 51(4):363-368

10. Bravo Mde L, Serpero LD, Barcelo A, Barbe F, Agusti A, Gozal D (2007) Inflammatory proteins in patients with obstructive sleep apnea with and without daytime sleepiness. Sleep Breath 11(3):177-185. https://doi.org/10.1007/s11325-007-0100-7

11. Minoguchi K, Yokoe T, Tazaki T, Minoguchi H, Oda N, Tanaka A, Yamamoto M, Ohta S, O'Donnell CP, Adachi M (2007) Silent brain infarction and platelet activation in obstructive 
sleep apnea. Am J Respir Crit Care Med 175(6):612-617. https ://doi.org/10.1164/rccm.200608-11410C

12. Nizankowska-Jedrzejczyk A, Almeida FR, Lowe AA, Kania A, Nastalek P, Mejza F, Foley JH, Nizankowska-Mogilnicka E, Undas A (2014) Modulation of inflammatory and hemostatic markers in obstructive sleep apnea patients treated with mandibular advancement splints: a parallel, controlled trial. J Clin Sleep Med 10(3):255-262. https://doi.org/10.5664/jcsm.3522

13. Peppard PE, Young T, Barnet JH, Palta M, Hagen EW, Hla KM (2013) Increased prevalence of sleep-disordered breathing in adults. Am J Epidemiol 177(9):1006-1014. https://doi. org/10.1093/aje/kws342

14. Unnikrishnan D, Jun J, Polotsky V (2015) Inflammation in sleep apnea: an update. Rev Endocrine Metab Disorders 16(1):25-34. https://doi.org/10.1007/s11154-014-9304-x

15. Yago T, Shao B, Miner JJ, Yao L, Klopocki AG, Maeda K, Coggeshall KM, McEver RP (2010) E-selectin engages PSGL-1 and CD44 through a common signaling pathway to induce integrin alphaLbeta2-mediated slow leukocyte rolling. Blood 116(3):485-494. https://doi.org/10.1182/blood-2009-12-259556

16. Carlow DA, Gossens K, Naus S, Veerman KM, Seo W, Ziltener HJ (2009) PSGL-1 function in immunity and steady state homeostasis. Immunol Rev 230(1):75-96. https://doi.org/10.1111/j.1600065X.2009.00797.x

17. Frenette PS, Denis CV, Weiss L, Jurk K, Subbarao S, Kehrel B, Hartwig JH, Vestweber D, Wagner DD (2000) P-Selectin glycoprotein ligand 1 (PSGL-1) is expressed on platelets and can mediate platelet-endothelial interactions in vivo. J Exp Med 191(8):1413-1422

18. Abadier M, Ley K (2017) P-selectin glycoprotein ligand-1 in T cells. Curr Opin Hematol 24(3):265-273. https://doi.org/10.1097/ moh.0000000000000331

19. Stampfuss JJ, Censarek P, Fischer JW, Kaber G, Rauch BH, Freidel K, Fischer U, Schulze-Osthoff K, Grosser T, Grandoch M, Schror K, Weber AA (2008) Complete downmodulation of $\mathrm{P}$-selectin glycoprotein ligand in monocytes undergoing apoptosis. Arterioscler Thromb Vasc Biol 28(7):1375-1378. https://doi. org/10.1161/atvbaha.108.166629

20. Kunos L, Horvath P, Kis A, Tarnoki DL, Tarnoki AD, Lazar Z, Bikov A (2018) Circulating survivin levels in obstructive sleep apnoea. Lung. https://doi.org/10.1007/s00408-018-0120-z

21. Faraday N, Scharpf RB, Dodd-o JM, Martinez EA, Rosenfeld BA, Dorman T (2001) Leukocytes can enhance platelet-mediated aggregation and thromboxane release via interaction of $\mathrm{P}$-selectin glycoprotein ligand 1 with P-selectin. Anesthesiology 94(1):145-151

22. Hidari KI, Weyrich AS, Zimmerman GA, McEver RP (1997) Engagement of P-selectin glycoprotein ligand-1 enhances tyrosine phosphorylation and activates mitogen-activated protein kinases in human neutrophils. J Biol Chem 272(45):28750-28756

23. Tinoco R, Otero DC, Takahashi AA, Bradley LM (2017) PSGL-1: A new player in the immune checkpoint landscape. Trends Immunol 38(5):323-335. https://doi.org/10.1016/j.it.2017.02.002
24. Leon-Cabrera S, Arana-Lechuga Y, Esqueda-Leon E, Teran-Perez G, Gonzalez-Chavez A, Escobedo G, Velazquez Moctezuma J (2015) Reduced systemic levels of IL-10 are associated with the severity of obstructive sleep apnea and insulin resistance in morbidly obese humans. Mediat Inflamm 2015:493409. https://doi. org/10.1155/2015/493409

25. Berry RB, Budhiraja R, Gottlieb DJ, Gozal D, Iber C, Kapur VK, Marcus CL, Mehra R, Parthasarathy S, Quan SF, Redline S, Strohl KP, Davidson Ward SL, Tangredi MM (2012) Rules for scoring respiratory events in sleep: update of the 2007 AASM Manual for the Scoring of Sleep and Associated Events. Deliberations of the Sleep Apnea Definitions Task Force of the American Academy of Sleep Medicine. J Clin Sleep Med 8(5):597-619. https://doi. org/10.5664/jcsm. 2172

26. McEvoy RD, Antic NA, Heeley E, Luo Y, Ou Q, Zhang X, Mediano O, Chen R, Drager LF, Liu Z, Chen G, Du B, McArdle N, Mukherjee S, Tripathi M, Billot L, Li Q, Lorenzi-Filho G, Barbe F, Redline S, Wang J, Arima H, Neal B, White DP, Grunstein RR, Zhong N, Anderson CS (2016) CPAP for prevention of cardiovascular events in obstructive sleep apnea. N Engl J Med 375(10):919-931. https://doi.org/10.1056/NEJMoa1606599

27. Stradling JR, Craig SE, Kohler M, Nicoll D, Ayers L, Nunn AJ, Bratton DJ (2015) Markers of inflammation: data from the MOSAIC randomised trial of CPAP for minimally symptomatic OSA. Thorax 70(2):181-182. https://doi.org/10.1136/thoraxjnl2014-205958

28. Chuang LP, Chen NH, Lin SW, Chang YL, Chao IJ, Pang JH (2013) Increased matrix metalloproteinases-9 after sleep in plasma and in monocytes of obstructive sleep apnea patients. Life Sci 93(5-6):220-225. https://doi.org/10.1016/j.lfs.2013.06.009

29. Cofta S, Wysocka E, Dziegielewska-Gesiak S, Michalak S, Piorunek T, Batura-Gabryel H, Torlinski L (2013) Plasma selectins in patients with obstructive sleep apnea. Adv Exp Med Biol 756:113-119. https://doi.org/10.1007/978-94-007-4549-0_15

30. Sahlman J, Miettinen K, Peuhkurinen K, Seppa J, Peltonen M, Herder C, Punnonen K, Vanninen E, Gylling H, Partinen M, Uusitupa M, Tuomilehto H (2010) The activation of the inflammatory cytokines in overweight patients with mild obstructive sleep apnoea. J Sleep Res 19(2):341-348. https://doi.org/10.111 1/j.1365-2869.2009.00787.x

31. Song D, Fang G, Greenberg H, Liu SF (2015) Chronic intermittent hypoxia exposure-induced atherosclerosis: a brief review. Immunol Res 63(1-3):121-130. https://doi.org/10.1007/s1202 6-015-8703-8

32. Bryant PA, Trinder J, Curtis N (2004) Sick and tired: does sleep have a vital role in the immune system? Nat Rev immunol 4(6):457-467. https://doi.org/10.1038/nri1369

Publisher's Note Springer Nature remains neutral with regard to jurisdictional claims in published maps and institutional affiliations. 